\title{
Ausschreibung: „Publizistenpreis der deutschen Bibliotheken 2021“
}

https://doi.org/10.1515/bd-2021-0018

Die bibliothekarischen Verbände Berufsverband Bibliothek Information e.V. (BIB), der Verein Deutscher Bibliothekarinnen und Bibliothekare e.V. (VDB) und der Deutsche Bibliotheksverband e.V. (dbv) schreiben gemeinsam den Publizistenpreis der deutschen Bibliotheken („Helmut-Sontag-Preis“) aus. Der Preis geht auf eine Initiative des ehemaligen dbv-Vorsitzenden Helmut Sontag zurück und wird seit 1987 verliehen. Er wird jährlich verliehen. Das Preisgeld beträgt 7.500 Euro.

Der „Publizistenpreis der deutschen Bibliotheken“ zeichnet Journalist ${ }^{\star}$ innen bzw. Redaktionsteams aller Medien aus, die die gesellschaftliche und kulturpolitische Bedeutung von Bibliotheken, ihre neuen Aufgaben und Rollen sowie ihre Vermittlung von Bildung, Kultur und Wissenschaft anschaulich, differenziert und gut recherchiert darstellen.

Wir bitten um Eigenbewerbungen bzw. Vorschläge von journalistischen Beiträgen, die in den Jahren 2019 und 2020 erschienen sind. Der gleiche Beitrag kann nicht ein weiteres Mal eingereicht werden. Weiterhin darf es sich nicht um eine Auftragsarbeit handeln.

Über die Vergabe des Preises entscheidet eine unabhängige Jury. Der Preis wird voraussichtlich im Rahmen der Abschlussveranstaltung des Bibliothekartages im Juni 2021 in Bremen verliehen.

\section{Einreichungen}

Eigenbewerbungen bzw. Vorschläge können bis Sonntag, den 28.02.2021 (Einsendeschluss) in elektronischer Form an baessler@bibliotheksverband.de gesendet werden.

Ein Bewerbungs- bzw. Vorschlagsformular steht unter https://www.biblio theksverband.de/fileadmin/user_upload/DBV/publizistenpreis/dateien/2021_ Bewerbungs-_bzw._Vorschlagsformular_Publizistenpreis.pdf zum Download zur Verfügung.

Weitere Informationen zum Publizistenpreis können unter http://www. publizistenpreis.de nachgelesen werden.

\section{Pressekontakt:}

Kristin Bäßler

Leitung Kommunikation / Pressesprecherin

Tel.: + 49 (0)30 6449899 25 | E-Mail: baessler@bibliotheksverband.de 